\section{Frederico Simões Barbosa: uma vida, uma obra, uma escola}

\author{
Frederico Simões Barbosa: a life, a work, a school \\ Frederico Simões Barbosa: una vida, una obra, \\ una escuela
}

1 Instituto Oswaldo Cruz, Fundação Oswaldo Cruz, Rio de Janeiro, Brasil.

Correspondência J. R. Coura

Laboratório de Doenças Parasitárias, Instituto Oswaldo Cruz, Fundação Oswaldo Cruz.

Av. Brasil 4365, Rio de Janeiro, RJ 21040-360, Brasil. coura@ioc.fiocruz.br
Conheci Frederico Simões Barbosa em 1964, no vigor dos seus 48 anos de idade, quando ele visitava o professor José Rodrigues da Silva, então diretor do Instituto Nacional de Endemias Rurais (INERu), e ele diretor pela segunda vez do Centro de Pesquisa Aggeu Magalhães (CPqAM). Ao entrar no gabinete do professor Rodrigues deparei-me com aquele homem alto, elegante, impecavelmente vestido com um terno claro, usando uma gravata borboleta, que salientava a sua face semissorridente de um gentleman, quando ele se dirigiu a mim dizendo "como vai, Coura?". Surpreendido, respondi: "muito bem, e o Senhor?". Eu não o conhecia, mas o professor Rodrigues tinha o hábito de falar dos seus assistentes aos seus amigos sem os apresentar. Desde esse dia me tornei um dos amigos daquele "Homem de fino trato, que a todos encantava pela sua delicadeza e simplicidade", como o definiu Eridan Coutinho no seu necrológio na Revista da Sociedade Brasileira de Medicina Tropical, em outubro de 20041 .

Frederico e Rodrigues da Silva discutiam o Plano Piloto de Controle da Esquistossomose, que contemplava as seguintes áreas: em Pernambuco (São Lourenço da Mata), com a coordenação de Frederico Simões Barbosa; na Bahia (Caatinga do Moura), coordenada por Aluízio Prata; Minas Gerais (Belo Horizonte), coordenada por Marcelo de Vasconcelos Coelho; e no Rio de Janeiro (Jacarepaguá), sob a coordenação de Solon de Camargo. O Plano Piloto tinha como
José Rodrigues Coura ${ }^{1}$

objetivo síntese: interromper a transmissão da esquistossomose por meio das seguintes atividades: (1) avaliar a dinâmica das populações de moluscos; (2) determinar os índices dos moluscos por cercarias e de pequenos roedores pelo Schistosoma mansoni; (3) emprego racional de moluscicidas, capazes de interromper a transmissão; (4) saneamento básico e educação sanitária; e (5) executar todas as medidas profiláticas aplicadas conjuntamente e, além disto, aplicar a terapêutica específica como complementação das medidas mencionadas 2. Coube a Frederico Simões Barbosa aplicar em São Lourenço da Mata o conjunto de medidas, como meta síntese do Plano Piloto. Em 1966, Frederico convidou um pequeno grupo para fazer uma breve avaliação das ações em São Lourenço da Mata. O grupo foi composto por mim, como clínico, especialista em doenças infecciosas, especialmente em esquistossomose, e doença de Chagas; Hortênsia de Hollanda, educadora sanitária, especializada em endemias rurais; Solon de Camargo, secretário do Plano Piloto, dirigido pelo professor Rodrigues da Silva; e o prefeito de São Lourenço da Mata. Verificamos que as ações sobre a dinâmica das populações de moluscos e seus índices de infecções, que medidas sanitárias, inclusive a construção de uma lavanderia coletiva, estavam perfeitas. Entretanto, a parte da educação sanitária, a cargo da Prefeitura de São Lourenço da Mata, tinha falhado. Por exemplo, chegamos à beira de um rio que atravessava a cidade e várias 
mulheres estavam lavando roupa com a água deste rio; perguntamos por que elas não lavavam a roupa na lavanderia? Responderam: "isso é para gente rica”, quando a lavanderia era para aquelas lavadeiras. Perguntamos às crianças que tomavam banho no rio se não havia doenças ali; um deles pulou de uma pedra e no salto para o rio disse: "tem xistosa doutor". Prova de que a educação estava falha. O prefeito se desculpou e disse que ia tomar as providências. Não sei se a promessa foi cumprida.

\section{Formação universitária}

A formação universitária de Frederico Simões Barbosa foi uma das mais perfeitas que conheci em toda a minha carreira de professor e pesquisador. Filho e neto de médicos, professores da Faculdade de Medicina de Recife (Pernambuco), Frederico graduou-se naquela escola médica em 1942. Ainda como estudante em 1939 estagiou com Samuel Pessoa, o grande professor de Parasitologia de São Paulo e do Brasil, e em Micologia com o professor Floriano de Almeida. Em 1945, viajou para os Estados Unidos com bolsa de estudos do Institute of Inter-American Affairs, onde permaneceu por 16 meses, obtendo o Master in Public Health na Universidade John Hopkins. Retornando ao Brasil, graduou-se em História Natural pela Universidade Católica de Pernambuco 1.

\section{Carreira acadêmica}

A carreira acadêmica de Frederico Simões Barbosa foi tão brilhante quanto ou mais do que a sua atuação como professor universitário. Fez quatro docências livres na Universidade Federal de Pernambuco (UFPE), respectivamente em Parasitologia em 1942, Microbiologia em 1950, Zoologia em 1953 e Medicina Preventiva em 1960, a mais ampla que conheci em minha longa vida universitária. Da mesma forma, os seus concursos para professor titular: de Higiene e Medicina Preventiva na UFPE, Epidemiologia na Escola Nacional de Saúde Pública da Fundação Oswaldo Cruz (ENSP/Fiocruz), Medicina da Comunidade na Universidade de Brasília (UnB) de 1972 a 1981, e de Medicina Preventiva da Universidade Federal de São Carlos (UFSC), em 1982.

\section{Cargos de direção e assessorias}

Frederico Simões Barbosa foi o primeiro diretor do CPqAM em 1950, na época vinculado à Divi- são da Organização Sanitária do Ministério da Saúde, e depois à Fiocruz, cargo no qual permaneceu até 1962 . Foi novamente diretor daquele centro de 1964 a 1968, quando o conheci. Foi perito em Doenças Parasitárias da Organização Mundial da Saúde (OMS) de 1960 a 1970, e da Organização das Nações Unidas para Alimentação e Agricultura (FAO) em 1961. Foi membro fundador da Sociedade Brasileira de Medicina Tropical (SBMT) a partir de 1962, sob a presidência do professor José Rodrigues da Silva, e presidente da SBMT no período de 1977-1978. Nos dois períodos em que foi diretor do CPqAM (1950 a 1962 e de 1964 a 1968), estruturou as atividades de pesquisa daquele centro, realizando estudos de aspectos básicos de taxonomia, biologia, ecologia de parasitos e moluscos hospedeiros intermediários de $S$. mansoni, sua epidemiologia e controle. Em 1981, foi contratado como assessor da Coordenadoria de Ciências da Saúde da Secretaria de Educação Superior do Ministério da Educação e Cultura (MEC), quando elaborou o Programa de Integração Docente-Assistencial, visando a estimular a formação profissional na área da saúde. Foi diretor da Faculdade de Ciências da Saúde da UnB de 1975 a 1976, e da ENSP/Fiocruz de 1985 a 1989. Finalmente, Frederico Simões Barbosa foi membro do Conselho Técnico-Científico da Fiocruz, como um dos mais destacados de 1979 a 1985 (Foto 1).

\section{Produção científica}

A produção científica de Frederico Simões Barbosa ultrapassa as suas atividades docente e administrativas. Publicou mais de 200 trabalhos científicos em revistas nacionais e internacionais de elevado conceito. Sempre procurou orientar uma atividade de pesquisa "translacional", aliando a pesquisa básica como, por exemplo, a taxinomia, ecologia e índices de infecção dos moluscos com cercáreas de S. mansoni, com a epidemiologia e o controle da esquistossomose, como no Plano Piloto de Controle da Esquistossomose. Uma nova espécie de trematoda (Echinostoma barbosai) foi criada em sua homenagem 1 . Por outro lado, sua produção foi bastante diversificada, trabalhando além da esquistossomose, com estudos sobre a sistemática de fungos, inclusive descrevendo uma nova espécie de hifomiceto de um caso de onicomicose, realizando ainda importantes trabalhos sobre taxonomia de culicídeos, descrevendo cinco novas espécies destes insetos, recebendo inclusive uma homenagem de Wirth \& Blanton com o nome de um maruin neotropical como Culicoides barbosai ${ }^{1}$. Podemos concluir que Frederico Simões Barbosa foi 
Foto 1

Conselho Técnico-científico da Fundação Oswaldo Cruz (1979-1985). A partir da esquerda: Zilton Andrade, Aluízio Prata, José Rodrigues Coura, Raymundo Moniz de Aragão, Carlos Chagas Filho, José Duarte, Otto Bier, Augusto Taunay, Heonir Rocha, Guilardo Martins Alves, Frederico Simões Barbosa, Gobert de Araújo Costa, Ernani Braga e Aristides Pacheco Leão. Rio de Janeiro, março de 1982 (Acervo da Casa de Oswaldo Cruz/Fundação Oswaldo Cruz).

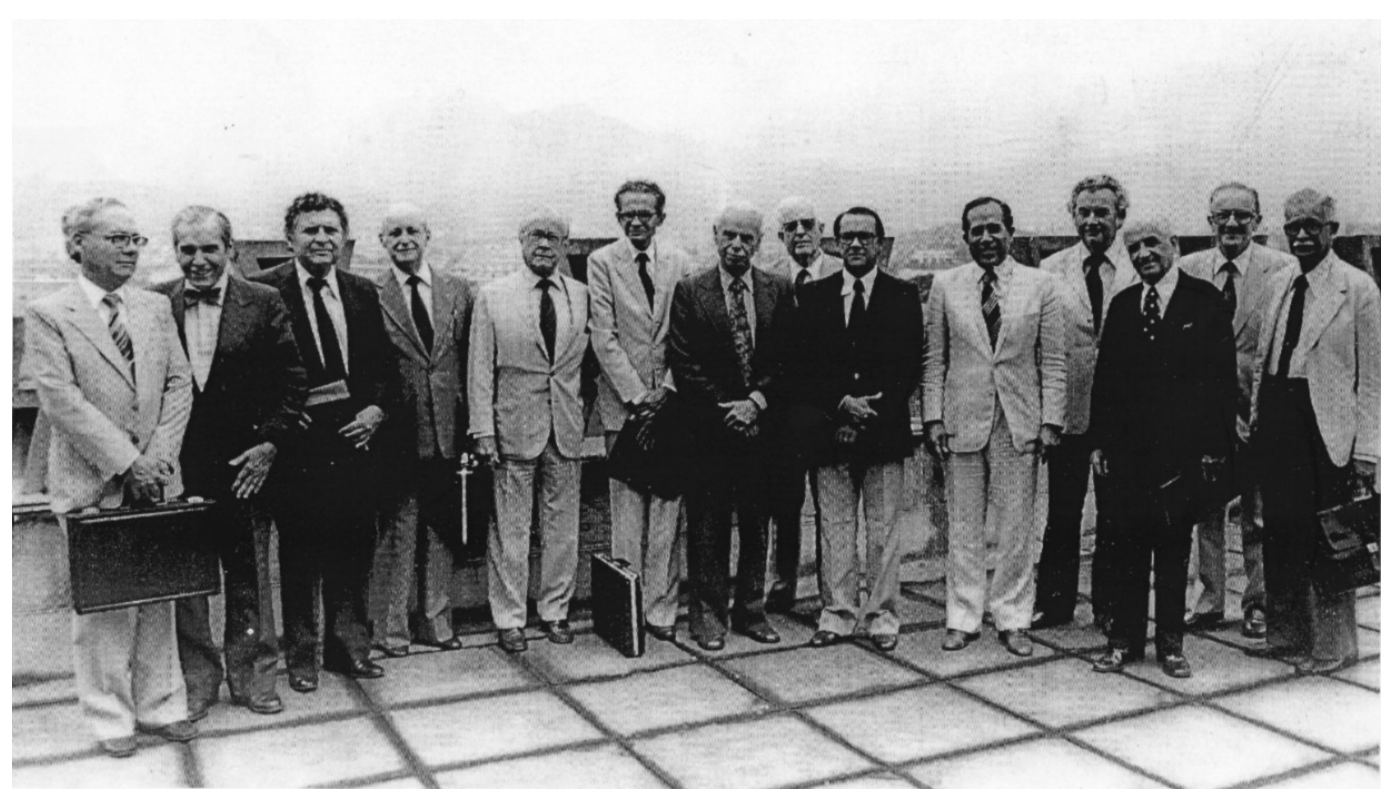

um professor e pesquisador de inteligência "gestáltica!", como demonstra em suas quatro livredocências (Parasitologia, Microbiologia, Zoologia e Medicina Preventiva).

\section{Uma síntese da personalidade e da cultura de Frederico Simões Barbosa}

Tomo a liberdade de transcrever a personalidade e a cultura de Frederico Simões Barbosa com o seu pronunciamento ao receber o título de Professor Honoris Causa da UnB, em 7 de novembro de 1995, que talvez alguns não conheçam:

"Há momentos inesquecíveis na vida de qualquer pessoa, sejam de incontida alegria ou de profundo pesar. Ambos deixam sempre marcadas lembranças na memória de cada um.

Gilberto Freyre dizia que o Homem é um ser tríbio, vivendo simultaneamente o Passado, o Presente e o Futuro. Lembro também as sábias lições do eminente cientista espanhol Ramon y Cajal em seu livro 'O mundo visto aos oitenta anos'.

Ao chegar-se a essa idade vive-se, de fato, muito mais intensamente o passado, quando afiaram nítidas lembranças. Assim, o ancião vive de suas recordações. O presente é visto difusamente através de representações pictóricas, fragmentadas, como que impressionistas. O futuro aparece como uma visão obscura do Cosmos.

Viver tribiamente é preciso, adaptar-se às novas contingências é necessário.

Hoje é um dia de muita alegria em minha trajetória de vida. A homenagem a mim conferida, eu a recebo com a humildade de quem procurou trilhar com simplicidade os caminhos da verdade e da dignidade. Agradeço ao Prof. Volney Garrafa as palavras generosas que proferiu a meu respeito, frutos que são de sua indulgência ornada por sua fulgurante e irrequieta inteligência.

Agradeço a todos os colegas desta Universidade, em particular aos membros deste colendo Conselho, a todos que fizeram e fazem esta Casa, aos amigos que aqui deixei.

Aos meus filhos, aqui presentes, o meu carinho e a certeza de que sem eles minha vida não teria sentido.

'Os acontecimentos têm alma', dizia o excelso poeta da língua portuguesa Fernando Pessoa. A alma está naqueles que construíram algo 
em momentos difíceis neste país contraditório. Não que queiramos ser 'Condutores da História', mas cada um de nós, nesta Universidade, colocou sua pedrinha, maior ou menor, no muro da modernidade.

Os fatos são recentes e do conhecimento de todos os que viveram os períodos sombrios, mais recentes, desta Universidade.

Aqui cheguei no início de 1972 atraído pelo novo, pelo moderno, por uma Universidade voltada para o futuro. As notícias que me chegavam a Genebra eram as mais animadoras, particularmente sobre a situação econômica do país (vivíamos o 'Milagre Brasileiro') e os acenos de abertura política.

Cedo verifiquei que o país pouco havia mudado. Em particular, percebi o sistema de informação montado na UnB para garantir a fidelidade ao regime. A UnB, situada a poucos quilômetros do Poder Central do Estado, teria que ter comportamento exemplar e competência para tal. Assim pensavam e agiam seus dirigentes. De fato, esta Universidade foi um dos mais competentes instrumentos políticos da Ditadura Militar no DF.

O desgaste produzido em todos nós que lutávamos por uma universidade livre, foi muito intenso e prolongado. Foram anos de perseguições, de sofrimento, prisões e tortura psicológica, administrados em doses diferenciadas para cada caso em particular. A Associação dos Docentes teve papel preponderante na resistência aos arreganhos da Ditadura.

(...)

...a Universidade de Brasília, foram feitos com vistas à implementação de um programa integrado de saúde comunitária utilizando-se a infra-estrutura local. Esta experiência foi muito útil para a montagem do modelo definitivo iniciado em 1975. Este 'Programa Integrado de Saúde Comunitária de Planaltina' teve as seguintes características:

1. Do ponto de vista conceitual foi uma proposta reformista avançada, através da qual se procurava criar um modelo realístico de atenção à saúde adaptado às condições da região onde foi implantado;

2. Do ponto de vista operacional o Programa atuou em integração com os serviços locais de saúde e desenvolvimento social (integração Docentel Assistencial), com hierarquização e nítida separação dos níveis e sub-níveis de atenção primária e secundária, utilizando pessoal auxiliar de saúde, procurando dar cobertura total à população e utilizando tecnologia apropriada;

3. Do ponto de vista estratégico, procurou, atuando na periferia do Distrito Federal, estender-se para outras áreas da capital do País constituindo um distrito docente-assistencial.
Com os propósitos acima e envolvendo-se com outras áreas docentes (particularmente as Ciências Sociais), o programa pretendia influir nas estruturas dos serviços de saúde, da docência e da pesquisa.

Hoje, vejo claramente os componentes utópicos de uma proposta implantada no reduto mais aguerrido da ditadura.

Enquanto o programa de Planaltina atuava através de um experimento avançado de ensino médico, o reitor de então (1976) publicava artigo na 'Folha de São Paulo' intitulado 'Nêmesis e a Medicina: precisa-se de um Flexner' que foi respondido, dias depois, com outro artigo publicado no mesmo jornal pelo eminente professor e saudoso sanitarista Gentile de Mello sob o título 'A Coragem do Senhor Reitor'. Ficou evidente, a partir desse momento, que o próprio Reitor traçava, a seu modo e sem rodeios, a política educacional da UnB na área da saúde (não importava o recuo de sete décadas). Estava, por consequência selado na Faculdade de Ciências da Saúde, o destino de programas educacionais que não aqueles oriundos do movimento Flexneriano de 1910.

Hoje, perto dos 80 anos, vivo como todos os brasileiros a perplexidade do momento político que atravessamos. A confusão era geral 'diria o $\mathrm{Ba}$ rão de Itararé'.

Faz-se necessário repensar o problema da universidade sob diferente ângulo, face aos mais recentes desdobramentos demográfico, sócio-político, científico/tecnológico e econômico que estão se sucedendo em nosso planeta.

O mundo vem mudando substancialmente. Os meios de comunicação tornam o globo cada vez menor, fazendo, paradoxalmente, com que as nações pobres se tornem mais vulneráveis. A violência, a poluição, a destruição do meio natural, a medicalização, o problema dos tóxicos que foram construções do primeiro mundo, adquiriram dimensões universais.

A comunidade científica tem o dever de ir além das denúncias, procurando atuar no sentido de pressionar as necessárias mudanças, sem o que o país continuará a passo lento e ignorado.

As universidades brasileiras têm papel de relevância. Sua missão não mais se assenta sobre o famoso tripé ensino/pesquisalextensão. Criar e transmitir o saber são suas precípuas obrigações. Entretanto, estas atividades só serão válidas se estiverem comprometidas com o bem estar social.

A produção científica deve ser simultaneamente um bem cultural e um instrumento de trabalho socialmente comprometido. As atividades docente e científica são parte da sociedade e só poderão ser entendidas como instrumentos de realização de objetivos sociais bem determinados. 
Seria oportuno lembrar a quem vem servindo o desenvolvimento econômico. A resposta é simples e clara, desde que o capitalismo moderno descobriu que os países podem crescer economicamente mantendo as desigualdades sociais. Isto é particularmente grave nos Países do Terceiro Mundo.

As novas tecnologias criadas com o advento da Ciência Moderna, trouxeram para a humanidade, nos primórdios deste século, esperanças de uma vida melhor. Ao final deste século sabemos que a ciência e a tecnologia não resolveram o problema fundamental da humanidade, a Qualidade de Vida em seu sentido ampliado, isto é, para todos.

Politicamente, o país foi subitamente arrastado para um sistema neoliberal, concentrador de renda e propiciador de desemprego em escala, como vem ocorrendo no mundo em geral e não apenas no terceiro mundo. A problemática é universal.

Por outro lado, o ensino não fez maiores progressos. No campo da saúde as propostas atuais são tímidas, preocupando-se as universidades mais com tecnologia e avaliação de qualidade, em vez de procurarem suas raízes nos campos político e sócio-econômico.

Outra realidade criada no país é a implementação do Sistema Único de Saúde (SUS) que poderá mudar o mercado de trabalho dos profissionais de saúde.

1. Coutinho EM. Frederico Simões Barbosa (1916 2004). Rev Soc Bras Med Trop 2004; 37:427-8.

2. Silva JR. Perspectivas de controle da esquistossomose no Brasil. Jornal Brasileiro de Medicina Tropical 1967; 1:13-7.
O mundo que se transforma exige que a educação tenha o sentido de preparar o Homem com consciência moral e ética capaz de valorizar a educação como instrumento de transformação. Isto implica em reconhecer que a educação deve ser encarada como prática social e a pedagogia como seu instrumento. Estão as Universidades preparadas para comandar estas mudanças?

Termino esta despretensiosa mensagem na velha e sábia Grécia quando Anaxímenes escrevia a Pitágoras:

'Como posso preocupar-me com o segredo das estrelas, quando tenho sempre presente a meus olhos a morte ou a escravidão?"' 3.

Finalmente, agradeço de coração à minha amiga Constança Simões Barbosa, uma das filhas do meu ídolo, pela oportunidade que me deu de homenagear o seu idolatrado pai no seu centenário.
3. Barbosa FS. Pronunciamento do Prof. Frederico Simões Barbosa, ao receber da Universidade de Brasília o título de Professor Honoris Causa, em 7/11/1995. http://www.unb.br/unb/titulos/frede rico_simoes.php.
Recebido em 09/Jun/2016

Aprovado em 14/Jun/2016 